\title{
Prevention of Alzheimer's Disease in Chinese Populations: Status, Challenges and Directions
}

\author{
L. Feng ${ }^{1}$, J. Li $i^{2}$, J.-T. Yu ${ }^{3}$, C. Zhang ${ }^{4}$, B. Yang ${ }^{5}$, B. Vellas ${ }^{9}$, C. Li $^{5,6,7,8}$ \\ 1. Department of Psychological Medicine, Yong Loo Lin School of Medicine, National University of Singapore, Singapore; 2. Center on Aging Psychology, \\ CAS Key Laboratory of Mental Health, Institute of Psychology, the Chinese Academy of Sciences, Beijing China; 3. Department of Neurology, Qingdao \\ Municipal Hospital, Qingdao University, Qingdao, Shandong, China; 4. Department of Neurology, Massachusetts General Hospital and Harvard \\ Medical School, Boston, USA; 5. Shanghai Key Laboratory of Psychotic Disorders, Shanghai Mental Health Center, Shanghai Jiao Tong University School \\ of Medicine, Shanghai 200030, China; 6. Center for Excellence in Brain Science and Intelligence Technology (CEBSIT), Chinese Academy of Science, \\ Shanghai, China; 7. Brain Science and Technology Research Center, Shanghai Jiao Tong University, Shanghai, China; 8. Bio-X Institutes, Key Laboratory \\ for the Genetics of Developmental and Neuropsychiatric Disorders (Ministry of Education), Shanghai Jiao Tong University, Shanghai, China (CL); \\ 9. Department of Geriatric \& Internal Medicine, Toulouse University, France
}

Corresponding Authors: Lei Feng, Department of Psychological Medicine, Yong Loo Lin School of Medicine, National University of Singapore, Singapore, pcmfl@nus.edu.sg; Chunbo Li, Shanghai Key Laboratory of Psychotic Disorders, Shanghai Mental Health Center, Shanghai Jiao Tong University School of Medicine, Shanghai, China, chunbo_ li@163.com

J Prev Alz Dis 2018;5(2):90-94

Published online March 21, 2018, http://dx.doi.org/10.14283/jpad.2018.14

Tn January 2018, the investigators from Eli Lily's EXPEDITION3 trial published their negative findings of a large phase 3 trial on the antibody Solanezumab (1). The lacking of statistically significant between-group difference on primary endpoint dampened enthusiasm again, and added the study to a long and growing list of failed trials (including EXPEDITION 1 and EXPEDITION2 from the same company) in the field of AD therapeutics. Without promising disease modifying agents, more and more clinicians and scientists in the field start to believe that prevention is better (and maybe easier) than treatment. In the West, scientists, lobbyists and advocacy groups are working hard in persuading the governments and funding agencies to invest more on efforts related to primary prevention of AD. A major study, the US POINTER will soon be initiated in 2018 in the U.S.

In the East, China is facing unprecedented fast population aging. With the largest elderly population in the World, we can foresee that AD will become a heavy burden to the health care system, families and the society and in the near future. Major policies and public health programs are urgently needed to curb the rising tide, and high quality research must be conducted as the prerequisite.

In this opinion paper, we will highlight the importance of $\mathrm{AD}$ and $\mathrm{AD}$ prevention in China, summarize existing knowledge on modifiable factors, provide an overview of published and ongoing prevention trials, and discuss $\mathrm{AD}$ biomarker research and the role of biomarkers in prevention trial. We also will point out promising future directions and propose the idea of establishing a Consortium for Dementia Prevention in Chinese (CDPC) as a potential forum and platform for the promotion of $\mathrm{AD}$ prevention research and practice in China.

\section{$\mathrm{AD}$ in China: rising tide in the next 30 years}

A key feature of population aging in China is a very rapid increase of the oldest-old. Based on data and projection form the United Nations, in 2015 there were 135.2 million elderly aged $\geq 65$ years in China, and 8.5 million of them are oldest-old (as defined as 85 years and above); the figure will become 358.9 million and 47.7 million respectively in 2050 (2). The proportion of oldestold in the elderly population would increase from $6.3 \%$ to $13.3 \%$ in three decades. This is critical for $\mathrm{AD}$, as it is well- known that the prevalence and incidence increase exponentially with older age. In the study conducted by Zhang and co-workers, the prevalence of $\mathrm{AD}$ for the age group $64-75$ years, $75-84$ years and $\geq 85$ years was $1.2 \%$, $5.7 \%$ and $23 \%$ respectively (3). Assuming age specific prevalence of $\mathrm{AD}$ remains the same, in 2050 China would have over 20 million AD patients.

\begin{tabular}{|c|c|c|c|}
\hline Age group & $\begin{array}{l}\text { Projected Population } \\
\text { by UN }\end{array}$ & $\begin{array}{l}\text { AD prevalence } \\
\text { based on Zhang } \\
\text { report }\end{array}$ & $\begin{array}{l}\text { Number of AD } \\
\text { patients in } 2050\end{array}$ \\
\hline $65-74$ & 167.2 million & $1.2 \%$ & 2.0 million \\
\hline $75-84$ & 144.0 million & $5.7 \%$ & 8.2 million \\
\hline$\geq 85$ & 47.7 million & $23 \%$ & 10.97 million \\
\hline
\end{tabular}

Total number of AD patients in China, 2050: 21.17 millions

\section{Modifiable risk and protective factors}

Prevention is not easy; it requires a good understanding of the natural history of the disease and a complete and comprehensive picture of various factors and markers that could be involved in the process (4). Studies based on the Chinese population have helped in establishing causal relationship between potential 
modifiable risk and protective factors.

To our best knowledge, at least 23 population-based prospective studies from 13 cohorts have been published till now to investigate the modifiable risk factors of cognitive disorders (including cognitive impairment, dementia, or Alzheimer's disease) in non-demented or MCI Chinese elderly. These participants were mainly from Mainland China (including Chongqing city, Beijing city, Shanghai city, Taiyuan city, Shandong Province or all over the country), Hong Kong, Taiwan, and Singapore. Three cohorts with larger sample size (over 10,000) and longer follow-up duration (6 to 16 years) are especially notable, including Cohort based on Taiwanese National Health Insurance Research Database $(5,6)$, Cohort based on All the Elderly Health Centers (EHCs) of the Department of Health in Hong Kong $(7,8)$, and Chinese Longitudinal Healthy Longevity Survey (CLHLS) in Mainland $(9,10)$. According to these studies, diabetes, sugar consumption, low vitamin D level were risk factor while education, social engagement, physical exercise, vegetables and fruit intake, and use of traditional Chinese medicine were found to be protective factors associated with incidence of cognitive disorders. In addition, tea consumption (protective), dietary exposure to acrylamide, osteoporosis, smoking, daily alcohol drinking (risky), occupation, cognitive activity (protective), chronic kidney disease, hypertension, plasma leptin level, and hyperlipidemia were also reported in other Chinesebased prospective studies to be associated with risk of cognitive impairment, dementia or dementia progression. The above factors are potential target for prevention trial and prevention programs at population level.

\section{Biomarkers}

Biomarkers are important for $\mathrm{AD}$, which can be used in both screening trial participants and evaluating trial outcomes as surrogate markers. Specifically, the biomarker abnormality occurs first in abeta levels which can be either an up-regulation in plasma or a down-regulation in cerebrospinal fluid (CSF) in usually cognitively normal individuals and can be detected by biochemical analysis (11). The next stage of biomarker abnormality was usually amyloid deposition in the brain detected by abeta positron-emission tomography (PET). Subsequently, the changes of biomarkers included neuronal injury, indicated by increased levels of CSF total and phosphorylated tau proteins, and cerebral atrophy revealed by structural magnetic resonance imaging (MRI), as well as neurodegeneration and synaptic dysfunction, detected by reduced fluorodeoxyglucose uptake through PET. The results of biomarker studies showed that they were correlated with different disease stages $(12,13)$, which thus correlated with and supported the changes in the "abeta hypothesis" (1417). Furthermore, the detection for blood-based abeta proteins as an $\mathrm{AD}$ biomarker was recently highlighted to be desirable due to its properties in the early stage and up-stream of disease pathology, as well as the minimally invasive and cost-effective features (11).

There have been several researches on $\mathrm{AD}$ biomarkers focused on the Chinese population. The results showed that the levels of biomarkers in Chinese population were also associated with different disease stages (18-23). Notably, evidence revealed the relationship of the abeta and tau proteins with $\mathrm{AD}$, as well as the association of plasma inflammatory molecules, e.g. soluble tumor necrosis factor receptors with AD $(19,24)$. Additionally, a study showed the association of the levels of plasma ceramides with AD (21). The mechanisms of these biomarkers in $\mathrm{AD}$ are pending further validation and exploration in different populations.

In summary, the results of biomarkers in Chinese population further supported the previously identified roles of biomarkers in $\mathrm{AD}$, which validated their highperformance values in association with other clinical data at different disease stages. For future directions, it is urgent to further investigate the roles of biomarkers on the system levels in association with the brain pathology and cognitive functions. Collectively, the results from these studies will be useful for future clinical intervention in both prevention and treatment purposes.

\section{Previous studies in China}

Although none of previous studies on prevention in China is at the scale comparable with the major prevention trials that have been conducted in western countries (FINGER, MAPT, etc.). Several published studies in China should be noticed as lessons have been learned and experiences have been gained from those important studies. There is now accumulating evidence from clinical trials on prevention of $\mathrm{AD}$ or cognitive decline in China, among which, a variety of prevention strategies have been investigated, including pharmacological, cognitive stimulus, physical exercise, nutrition and lifestyle interventions. Some strategies are similar to those of western studies, such as cognitive training (25-31), aerobic exercise (32-35), multi-domain lifestyle (36) and nutritional intervention (37-40), while others are Chinese cultural related interventions. It includes the use of traditional Chinese medicine (TCM) such as Chinese herbs (41-43) and acupuncture or acupressure $(44,45)$, as well as traditional Chinese sports and pastimes such as Tai chi and Baduanjin (4649), calligraphy (50), finger exercise (51), etc. Notably, a multi-domain intervention comprised of cognitive training, Tai Chi exercise and psycho-social counselling, has been conducted in healthy elderly people recruited from communities in Beijing. Significant improvement was observed in both cognitive and brain functions in multi-domain intervention group compared to active control group (52-54). Overall, these trials in China have provided potential prevention strategies listed above. 
Despite the promising results from the published trials, there are several limitations. First, most of these trials are single-center studies with small sample size and short follow-up periods. Second, most trials published in Chinese medical journals are at high risk of bias associated with inadequate or unclear allocation concealment and lack of blind assessment. Furthermore, nearly all trials measured cognitive performance rather than clinically meaningful endpoint, such as reduction of incidence of Alzheimer's disease as the primary endpoint outcome.

Therefore, further evidence from larger and longer multi-center trials is needed to confirm longterm effectiveness and establish the individualized optimum design or dose of feasible, affordable, and safe interventions. Notably, Chinese cultural related interventions combined with new technology will hold great promise for preservation of cognitive function among the Chinese elderly.

\section{Emerging new studies}

As noted above, there are growing evidence on trainable protective factors and modifiable risk factors of cognitive decline and dementia. Therefore from a population-based perspective, it is imperative to conduct multi-domain intervention targeting at those risk and protective factors to prevent or delay the onset of dementia. The Finnish FINGER study has demonstrated for the first time in a randomized controlled trial that an intensive multidomain lifestyle intervention among older at-risk individuals may help prevent cognitive decline. Multidomain intervention to prevent and delay dementia is still in its infancy in China. Inspired by the FINGER study, China-FINGER was recently initiated. The ChinaFINGER aims to test whether a multidomain intervention program sensitive to Chinese lifestyle and socialcultural factors will prevent cognitive decline and delay dementia among elderly people in both rural and urban areas. The intervention program consists of multiple components: (1) lifestyle and nutritional guidelines; (2) intellectual and social activities; (3) physical exercise; (4) regular monitoring and management of major cardiometabolic risk factors. The rural and urban parts of China-FINGER are organized by multidisciplinary research teams from Shangdong Provincial Hospital led by Yifeng Du, and from Institute of Psychology, Chinese Academy of Sciences led by Juan Li, in collaboration with senior researchers from Karolinska Institute (Chengxuan Qiu and Miia Kivipelto). This pioneering national mutidomain intervention program is supported by Chinese Ministry of Science and Technology, Chinese National Science Foundation, Chinese Academy of Sciences and Beijing Municipal Science \& Technology Commission.

There are also new studies on novel single intervention approaches. In Singapore, Lei Feng and colleagues are currently conducting a large scale RCT to assess the efficacy and biological mechanisms of choral singing in preventing cognitive decline among community-living elderly who are at high risk of dementia (ClinicalTrials. gov Identifier NCT02919748). Square dancing has become the most popular leisure activity among Chinese elderly women, and it has been estimated to have over 100 million elderly practitioners in mainland China (55). In Beijing, a team led by Juan Li in Chinese Academy of Sciences is conducting a RCT trial (ChiCTRIOR-17011668) to assess how Square dancing, a culturally adapted aerobic dance, could enhance cognitive health and hippocampal plasticity for community-dwelling older adults. Another example of such novel single intervention study is a collaborative project on the potential role of Chinese ink painting in $\mathrm{AD}$ prevention. This study is a collaboration between Singapore, Shanghai and Boston. The trial will be conducted in both Singapore (site PI: Lei Feng) and Shanghai (site PI: Chunbo Li) using identical study protocols. AD biomarkers will be measured in MGH (Lab PI: Can Zhang). Another study, Tea for Alzheimer's Prevention (TAP) trial, is also being planned in Singapore. The study is based on growing evidence of cognitive benefits of tea drinking (56-61) and will involve collaborators from the Europe (Bruno Vellas) and the U.S. (Can Zhang).

More importantly, research findings should be translated into community-based programs to benefit the population. Such a community-based program, the Singapore Dementia Prevention Program (DPP) (62) has been established by Ee-Heok Kua and a group of academics, practitioners and volunteers; the program aims to apply evidence-based interventions in the community through collaborations with various senior activity centers and voluntary welfare organizations. Such community-based programs could be established in China in the near future.

\section{Future directions}

We project that there are over 20 million $\mathrm{AD}$ patients in China by 2050. With this rising tide, we urge that more high-quality research should be funded and conducted in the next decade to guide policymaking and public health measures. Findings from those studies will enable the design and implementation of effective prevention programs at population level. To curb the emerging dementia epidemic in China and other major Chinese populations, we propose to form the Consortium for Dementia Prevention in Chinese (CDPC). This Consortium will serve as platform for the sharing of information, protocols and data, and as a forum for the communication of new ideas and the conceptualization of large collaborative studies. We invite colleagues who are focusing on larger prospective cohort studies and interventional trials in $\mathrm{AD}$, dementia, mild cognitive impairment and cognitive aging to join the Consortium. 
Acknowledgement: Lei Feng received grant support from the National Innovation Challenge on Active and Confident Ageing Programme, Ministry of Health of Singapore (Award No.: MOH/NIC/COG06/2017) and the National Medical Research Council of Singapore (Award No.: number NMRC/ TA/0053/2016); Chunbo Li received grant support from the Shanghai Mental Health Center clinical research fund (CRC2017ZD01).

Conflict of Interests: none reported.

\section{References}

1. Honig LS, Vellas B, Woodward M, Boada M, Bullock R, Borrie M, Hager K Andreasen N, Scarpini E, Liu-Seifert H, Case M, Dean RA, Hake A, Sundel K, Hoffmann VP, Carlson C, Khanna R, Mintun M, DeMattos R, Selzler KJ Siemers E. Trial of Solanezumab for Mild Dementia Due to Alzheimer's Disease. New England Journal of Medicine 2018;378, 321-330.

2. United Nations, Department of Economic and Social Affairs, Population Division, 2017. World Population Prospects: The 2017 Revision, custom data acquired via website.

3. Zhang ZX, Zahner GE, Roman GC, Liu J, Hong Z, Qu QM, Liu XH, Zhang XJ, Zhou B, Wu CB, Tang MN, Hong X, Li H. Dementia subtypes in China: prevalence in Beijing, Xian, Shanghai, and Chengdu. Arch Neurol 2005;62, 447-453.

4. Feng L, Chiu H, Chong M-Y, Yu X, Kua E-H. Dementia in Chinese populations: Current data and future research. Asia-Pacific Psychiatry 2011;3, 109-114.

5. Chen $\mathrm{KH}$, Yeh MH, Livneh H, Chen BC, Lin IH, Lu MC, Tsai TY, Yeh CC. Association of traditional Chinese medicine therapy and the risk of dementia in patients with hypertension: a nationwide population-based cohort study. BMC Complement Altern Med 2017;17, 178 .

6. Liu CT, Wu BY, Hung YC, Wang LY, Lee YY, Lin TK, Lin PY, Chen WF, Chiang JH, Hsu SF, Hu WL. Decreased risk of dementia in migraine patients with traditional Chinese medicine use: a population-based cohort study. Oncotarget 2017;8, 79680-79692.

7. Lee ATC, Richards M, Chan WC, Chiu HFK, Lee RSY, Lam LCW. Lower risk of incident dementia among Chinese older adults having three servings of vegetables and two servings of fruits a day. Age Ageing 2017;46, 773-779.

8. Lee AT, Richards M, Chan WC, Chiu HF, Lee RS, Lam LC. Intensity and Types of Physical Exercise in Relation to Dementia Risk Reduction in Community-Living Older Adults. J Am Med Dir Assoc 2015;16, 899 e891-897.

9. Gao M, Kuang W, Qiu P, Wang H, Lv X, Yang M. The time trends of cognitive impairment incidence among older Chinese people in the community: based on the CLHLS cohorts from 1998 to 2014. Age Ageing 2017:46, 787-793.

10. Yang L, Martikainen P, Silventoinen K, Konttinen H. Association of socioeconomic status and cognitive functioning change among elderly Chinese people. Age Ageing 2016;45, 674-680.

11. Nakamura A, Kaneko N, Villemagne VL, Kato T, Doecke J, Dore V, Fowler C, Li QX, Martins R, Rowe C, Tomita T, Matsuzaki K, Ishii K, Arahata Y, Iwamoto S, Ito K, Tanaka K, Masters CL, Yanagisawa K. High performance plasma amyloid-beta biomarkers for Alzheimer's disease. Nature 2018;554, 249-254.

12. Jack CR, Jr., Knopman DS, Jagust WJ, Shaw LM, Aisen PS, Weiner MW, Petersen RC, Trojanowski JQ. Hypothetical model of dynamic biomarkers of the Alzheimer's pathological cascade. Lancet Neurol 2010;9, 119-128.

13. Sperling RA, Aisen PS, Beckett LA, Bennett DA, Craft S, Fagan AM, Iwatsubo T, Jack CR, Jr., Kaye J, Montine TJ, Park DC, Reiman EM, Rowe CC, Siemers E, Stern Y, Yaffe K, Carrillo MC, Thies B, Morrison-Bogorad M, Wagster MV, Phelps $\mathrm{CH}$. Toward defining the preclinical stages of Alzheimer's disease: recommendations from the National Institute on Aging-Alzheimer's Association workgroups on diagnostic guidelines for Alzheimer's disease. Alzheimers Dement 2011;7, 280-292.

14. Hardy J, Selkoe DJ. The amyloid hypothesis of Alzheimer's disease: progress and problems on the road to therapeutics. Science 2002;297, 353-356.

15. Bertram L, Tanzi RE. Thirty years of Alzheimer's disease genetics: the implications of systematic meta-analyses. Nat Rev Neurosci 2008;9, 768-778.

16. Gandy S. The role of cerebral amyloid beta accumulation in common forms of Alzheimer disease. J Clin Invest 2005;115, 1121-1129.

17. Choi SH, Kim YH, Hebisch M, Sliwinski C, Lee S, D'Avanzo C, Chen H, Hooli B, Asselin C, Muffat J, Klee JB, Zhang C, Wainger BJ, Peitz M, Kovacs DM, Woolf CJ, Wagner SL, Tanzi RE, Kim DY. A three-dimensional human neural cell culture model of Alzheimer's disease. Nature 2014;515, 274-278.

18. Chou CT, Liao YC, Lee WJ, Wang SJ, Fuh JL. SORL1 gene, plasma biomarkers, and the risk of Alzheimer's disease for the Han Chinese population in Taiwan. Alzheimers Res Ther 8, 53 .

19. Zhang J, Peng M, Jia J. Plasma amyloid-beta oligomers and soluble tumo necrosis factor receptors as potential biomarkers of AD. Curr Alzheimer Res 2014;11, 325-331.

20. Yuan L, Liu J, Ma W, Dong L, Wang W, Che R, Xiao R. Dietary pattern and antioxidants in plasma and erythrocyte in patients with mild cognitive impairment from China. Nutrition 2016:32, 193-198.

21. Xing Y, Tang Y, Zhao L, Wang Q, Qin W, Zhang JL, Jia J. Plasma Ceramides and Neuropsychiatric Symptoms of Alzheimer's Disease. J Alzheimers Dis 2016;52, 1029-1035.

22. Shea YF, Chu LW, Zhou L, Li WM, Lin OY, Chan MN, Xu A, Wong R, Ho TY, Liu KW, Ha J, Daniel TW, Song YQ, Lam KS. Cerebrospinal fluid biomarkers of Alzheimer's disease in Chinese patients: a pilot study. Am J Alzheimers Dis Other Demen 2013;28, 769-775.

23. Liu B, Tang Y, Shen Y, Cen L, Han M. Cerebrospinal fluid tau protein in differential diagnosis of Alzheimer's disease and vascular dementia in Chinese population: a meta-analysis. Am J Alzheimers Dis Other Demen 2014;29, 116-122.

24. Bai L, Song N, Yu J, Tan L, Shen Y, Xie J, Jiang H. Elevated plasma levels of soluble TNFRs and TACE activity in Alzheimer's disease patients of Northern Han Chinese descent. Curr Alzheimer Res 2013;10, 57-62.

25. Kwok T, Wong A, Chan G, Shiu YY, Lam KC, Young D, Ho DW, Ho F. Effectiveness of cognitive training for Chinese elderly in Hong Kong. Clin Interv Aging 2013;8, 213-219.

26. Cheng Y, Wu W, Feng W, Wang J, Chen Y, Shen Y, Li Q, Zhang X, Li C. The effects of multi-domain versus single-domain cognitive training in nondemented older people: a randomized controlled trial. BMC Med 2012;10, 30

27. Zhuang JP, Fang R, Feng X, Xu XH, Liu LH, Bai QK, Tang HD, Zhao ZG, Chen SD. The impact of human-computer interaction-based comprehensive training on the cognitive functions of cognitive impairment elderly individuals in a nursing home. J Alzheimers Dis 2013;36, 245-251.

28. Feng $\mathrm{W}$, Li CB, Chen $\mathrm{Y}$, Cheng $\mathrm{Y}, \mathrm{Wu}$ WY. Integrative cognitive training for healthy elderly Chinese in community: A controlled study. Biomedical Research (India) 2013;24, 223-229.

29. Chen B, Wei Y, Deng W, Sun S. The Effects of Cognitive Training on Cognitive Abilities and Everyday Function: A 10-Week Randomized Controlled Trial. Int J Aging Hum Dev 2018;86, 69-81.

30. Li, B., Zhu, X., Hou, J., Chen, T., Wang, P., \& Li J (2016). Combined Cognitive Training vs. Memory Strategy Training in Healthy Older Adults. Frontiers in Psychology, 7, 834. doi: 10.3389/ fpsyg.2016.00834.

31. Niu YN, Zhu XY, Li J, Fu JN (2016). The ERP Effects of Combined Cognitive Training on Intention-based and Stimulus-based Actions in Older Chinese Adults, Frontiers in Psychology, 7, 1670. doi: 10.3389/fpsyg.2016.01670.

32. Kwok TC, Lam KC, Wong PS, Chau WW, Yuen KS, Ting KT, Chung EW, Li JC, Ho FK. Effectiveness of coordination exercise in improving cognitive function in older adults: a prospective study. Clin Interv Aging 2011;6, 261267.

33. Law LL, Barnett F, Yau MK, Gray MA. Effects of functional tasks exercise on older adults with cognitive impairment at risk of Alzheimer's disease: a randomised controlled trial. Age Ageing 2014;43, 813-820.

34. Lu J, Sun M, Liang L, Feng Y, Pan X, Liu Y. Effects of momentum-based dumbbell training on cognitive function in older adults with mild cognitive impairment: a pilot randomized controlled trial. Clin Interv Aging 2016;11, 9-16.

35. Zhang $X, \mathrm{Ni} X$, Chen P. Study About the Effects of Different Fitness Sports on Cognitive Function and Emotion of the Aged. Cell Biochemistry and Biophysics 2014;70, 1591-1596.

36. Lam LC, Chan WC, Leung T, Fung AW, Leung EM. Would older adults with mild cognitive impairment adhere to and benefit from a structured lifestyle activity intervention to enhance cognition?: a cluster randomized controlled trial. PLoS One 2015;10, e0118173.

37. Zhang Y-P, Miao R, Li Q, Wu T, Ma F. Effects of DHA Supplementation on Hippocampal Volume and Cognitive Function in Older Adults with Mild Cognitive Impairment: A 12-Month Randomized, Double- Blind, PlaceboControlled Trial. Journal of Alzheimers Disease 2017;55, 497-507.

38. Ma F, Wu T, Zhao J, Han F, Marseglia A, Liu H, Huang G. Effects of 6-Month Folic Acid Supplementation on Cognitive Function and Blood Biomarkers in Mild Cognitive Impairment: A Randomized Controlled Trial in China. J Gerontol A Biol Sci Med Sci 2016;71, 1376-1383.

39. Bo Y, Zhang X, Wang Y, You J, Cui H, Zhu Y, Pang W, Liu W, Jiang Y, Lu O. The n-3 polyunsaturated fatty acids supplementation improved the cognitive function in the Chinese elderly with mild cognitive impairment: A doubleblind randomized controlled trial. Nutrients $9,2017$.

40. Kwok TC, Lam LC, Sea MM, Goggins W, Woo J. A randomized controlled trial of dietetic interventions to prevent cognitive decline in old age hostel residents. Eur J Clin Nutr 2012;66, 1135-1140.

41. Yu E, Liao Z, Tan Y, Qiu Y, Zhu J,Shi M, et al. Preventive effects of Haishe capsules for the conversion of amnestic mild cognitive impairment to Alzheimer's disease. Chin J Geriatr 2017,36(3):278-281.

42. Zhou R, Lin S, Yuan Q. Clinical study on effect of Shenyin oral liquid in treating mild cognitive impairment.Chin J Integr Trad West Med 2007,27(9):793-795.

43. Zhou P, Ge W, Liu W, Xia L. A clinical study of Ruiqi Tablet for prevention of aging and improving memory. JournaI of Chinese Materia Medica 2002,27(11):873-875.

44. Tan TT, Wang D, Huang JK, Zhou XM, Yuan X, Liang JP, Yin L, Xie HL, Jia XY, Shi J, Wang F, Yang HB, Chen SJ. Modulatory effects of acupuncture on 
brain networks in mild cognitive impairment patients. Neural Regen Res 2017;12, 250-258.

45. Zeng H, Liu M, Wang P, Kang J, Lu F, Pan L. The Effects of Acupressure Training on Sleep Quality and Cognitive Function of Older Adults: A 1-Year Randomized Controlled Trial. Res Nurs Health 2016;39, 328-336.

46. Lam LCW, Chau RCM, Wong BML, Fung AWT, Tam CWC, Leung GTY, Kwok TCY, Leung TYS, Ng SP, Chan WM. A 1-Year Randomized Controlled Trial Comparing Mind Body Exercise (Tai Chi) With Stretching and Toning Exercise on Cognitive Function in Older Chinese Adults at Risk of Cognitive Decline. Journal of the American Medical Directors Association 2012;13.

47. Lam LC, Chau RC, Wong BM, Fung AW, Lui VW, Tam CC, Leung GT, Kwok $\mathrm{TC}$, Chiu HF, Ng S, Chan WM. Interim follow-up of a randomized controlled trial comparing Chinese style mind body (Tai Chi) and stretching exercises on cognitive function in subjects at risk of progressive cognitive decline. Int J Geriatr Psychiatry 2011;26, 733-740.

48. Siu MY, Lee DTF. Effects of tai chi on cognition and instrumental activities of daily living in community dwelling older people with mild cognitive impairment. BMC Geriatr 2018;18, 37.

49. Tao J, Liu J, Liu W, Huang J, Xue X, Chen X, Wu J, Zheng G, Chen B, Li M, Sun S, Jorgenson K, Lang C, Hu K, Chen S, Chen L, Kong J. Tai Chi Chuan and Baduanjin Increase Grey Matter Volume in Older Adults: A Brain Imaging Study. J Alzheimers Dis 2017;60, 389-400.

50. Kwok TC, Bai X, Kao HS, Li JC, Ho FK. Cognitive effects of calligraphy therapy for older people: a randomized controlled trial in Hong Kong. Clin Interv Aging 2011;6, 269-273.

51. Chen $Y$, Liu H, Jiang W, Zhang X, Deng Z. The effectiveness of finger exercise in community-dwelling elderly with mild cognitive impairment. Journal of Nursing Science 2016;31(17):90-92.

52. Yin S., Zhu X., Li R., Niu Y., Wang B., Zheng Z., Huang X., Huo L., Li J, 2014. Intervention-induced enhancement in intrinsic brain activity in healthy older adults. Scientific Reports, $2014 ; 4: 7309$. doi: 10.1038/srep07309.

53. Li R, Zhu X, Yin S, Niu Y, Zheng Z, Huang X, Wang B, Li J* (2014). Multimodal intervention in older adults improves resting-state functional connectivity between the medial prefrontal cortex and medial temporal lobe.
Frontiers in Aging Neuroscience 8:39. doi: 10.3389/ fnagi.2014.00039.

54. Zheng Z, Zhu X, Yin S, Wang B, Niu Y, Huang X, Li R*, Li J* (2015). Combined Cognitive-Psychological-Physical Intervention Induces Reorganization of Intrinsic Functional Brain Architecture in Older Adults. Neural Plasticity.

55. GBTIMES Beijing. (2017, July, 18). Square dancing added to China's National Games. Retrieved from https://gbtimes.com/square-dancing-added-chinasnational-games. doi:10.1155/2015/713104.Brain

56. Feng L, Chong MS, Lim WS, Gao Q, Nyunt MS, Lee TS, Collinson SL, Tsoi T, Kua EH, Ng TP. Tea Consumption Reduces the Incidence of Neurocognitive Disorders: Findings from the Singapore Longitudinal Aging Study. J Nutr Health Aging 2016;20, 1002-1009.

57. Feng L, Chong MS, Lim WS, Lee TS, Kua EH, Ng TP. Tea for Alzheimer Prevention. J Prev Alzheimers Dis 2015;2, 136-141.

58. Feng L, Ng TP, Kua EH, Preedy VR. Tea and cognitive function of elderly people - evidence from neurobiology and epidemiology In Tea in Health and Disease Prevention, Preedy VR, ed. Elsevier Inc. , London, 2012;pp. 1132511336.

59. Feng L, Li J, Ng TP, Lee TS, Kua EH, Zeng Y. Tea drinking and cognitive function in oldest-old Chinese. The Journal of Nutrition, Health \& Aging 2012;16, 754-758.

60. Song J, Xu H, Liu F, Feng L. Tea and Cognitive Health in Late Life: Current Evidence and Future Directions. Journal of Nutrition Health \& Aging 2012;16, 31-34.

61. Zeng Y, Chen H, Ni T, Ruan R, Feng L, Nie C, Cheng L, Li Y, Tao W, Gu J, Land KC, Yashin A, Tan Q, Yang Z, Bolund L, Yang H, Hauser E, Willcox DC, Willcox BJ, Tian X-L, Vaupel JW. GxE Interactions between FOXO Genotypes and Tea Drinking Are Significantly Associated with Cognitive Disability at Advanced Ages in China. The Journals of Gerontology Series A: Biological Sciences and Medical Sciences 2015;70, 426-433.

62. Wu DX, Feng L, Yao SQ, Tian XF, Mahendran R, Kua EH. The early dementia prevention programme in Singapore. Lancet Psychiatry 2014;1, 9-11. 